the large lacunæ upon its upper surface uninjured. Upon injecting the water through the vein a second time, it flowed freely from the cut surfaces of the corpus spongiosum urethræ, and it trickled from the orifices of the lacunæ, especially from that of the lacuna magna. My next care was to throw in a fine injection, which pursued the course of the other fluids, escaping from the mouths of the lacunæ as before. The preparation was then dried and preserved." I should have mentioned, that before injecting the penis with wax, I inflated both corpora cavernosa with air, in the rough manner usually done in the dissecting-room.

Turning over in my mind the facts which this preparation demonstrated, I adopted the plan of taking blood from the penis by opening its dorsal vein, and with a success which has fully warranted me to persevere in this practice for more than three years. The communications which exist between the veins of the corpus spongiosum and the dorsal vein are very direct and numerous; and probably there is no part of the body where blood can be so speedily obtained from the direct seat of inflammation, by venesection, as in the urethra. Although the fluids which were injected in the preparation I have alluded to, and which is in our museum at the Westminster Hospital School of Medicine, escaped through the lacunæ of the urethra, yet I do not wish you to infer that any direct communication takes place in the natural state of the parts, between the radicles of the vein and the mucous follicles; in this case the membranes which separated them were doubtlessly torn through by the force of the air thrown into the vein in the first instance, but the fact clearly demonstrates how intimately connected the ducts and the blood-vessels are; and very probably when hæmorrhage occurs from the urethra, from acute inflammation, as it sometimes does in gonorrhœa, the blood escapes through the lacunæ, the membranes separating these ducts, and the veins being torn through in the first instance from the con. gestion of the blood-vessels.

Besides the lacuna magna in the fossa navicularis there are numerous other lacunæ, with the openings of which the free surface of the urethra is studded. The largest of these are always found to occupy the upper surface of the urethra, whilst the ducts of the prostate gland, those of the testicles, and seminal vesicles, and those of Cowper's glands, are placed upon its under surface-facts which are always borne in mind by the surgeon, when introducing instruments along the urethra. The mouths of all these openings are directed forward, or towards the distal orifice.

The length of the three divisions of the urethra is of some importance for you to bear in mind; and I may here state there is some discrepancy in your dissecting books upon this head. In the adult, where the prostate gland is fully developed, the length of the prostatic portion of the urethra seldom exceeds an inch and a quarter; the membranous portion of the urethra is not so long, being in general not more than half an inch; and the remaining portion of the canal which is enclosed by the corpus spongiosum depends for its length upon the development of the penis, which scarcely, however, makes a difference in most instances of more than an inch in length. The dimensions and length of the prostatic and membranous portions of the urethra are of more practical importance to be acquainted with than that of the spongy portion.

The prepuce affords one of the best examples in the body of the continuity of skin and mucous membrane, or rather of the insensible manner in which the one is gradually lost in the other. The fine, delicate skin which envelops the penis, extends for some length beyond the organ, and is reflected upon itself in such a manner as to form a covering for the glans penis. The mucous membrane of the urethra is continued from the external orifice over the surface of the glans, and at its base, or as it is called the corona glandis, it is continuous with the reflected layer of the prepuce.

In some individuals, the prepuce habitually is worn over the glans, and here its inner surface and the membrane covering the glans have all the characters of mucous membranes, and subject the individuals to balanitis, excoriations, phymosis, \&c.; in others the surface of the glans is always denuded, and the prepuce thrown back; such individuals seldom are subjected to these annoying diseases, and the parts have all the characters of skin.

Gentlemen, the time I have taken up in speaking of the anatomy and functions of these parts forbids me to enter upon the subject of gonorrhœa until our next meeting. I shall not, however, offer you any apologies for having dwelt upon what I know some of you are already acquainted with; because, as I have said before, it is always necessary to have a clear understanding of the meaning of the anatomical terms by which we distinguish the various parts of an organ, previously to speaking of its diseases.

\section{FRACTURE OF THE SKULL.-COMPRES-} SION OF THE BRAIN.

\section{TO THE EDITORS OF THE PROVINCIAL MEDICAL JOURNAL.}

Gretremen,--In a paper which I wrote on injuries of the head, in the ninth volume of the Transactions of the Provincial Medical and Surgical Association, I endeavoured to point out some characteristic signs whereby the surgeon can judge of the existence of fracture at the base of the skull. The first of the two cases Isend you is a well-marked case of this description. The last case is one where symptoms of compression of the brain came on two days after an accident, without any previous indications of injury to the head, - which symptoms rapidly gave way under the influence of mercury. If you consider these cases of sufficient importance, I shall be glad of their insertion in your Journal.

Jan. 1813.

Your obedient servant, JOHN M. BANNer.

CASE I.-Joseph Bradbury, aged 26, was admitted into the Liverpool Northern Hospital on June 4, 1842.

History.-By trade he is an iron-founder, of very temperate habits. About an hour and a half before his admission into the hospital, he was struck senseleas by a part of a large boiler falling and striking him the side of the head; he remained in a state of 
insensibility for two or three minutes; afterwards he was able to walk, supported by two men, suffering at intervals from vomiting.

Appearances and Symptoms.-There is a wound of the scalp eight inches long, extending from the centre of the right parietal bone to the nape of the neck; the bone is deprived of its pericranium for an inch or more in extent; there is neither fracture nor fissure observable at this part. There is a small wound on the left cheek. There is slight ecchymosis of the upper lids of both eyes, and also of the conjunctiva of the left eye. There is considerable hæmorrhage from the right ear, right nostril, and mouth, which has continued ever since the accident. The pupils are natural, and act freely on the admission of light; the pulse is quick and weak, the surface cold, the countenance pale.

Treatment.-The edges of the wound were drawn together; warmth was applied to the surface; warm drink with small quantities of stimuli were given. An aperient in the morning.

5. He slept a little during the night; complains of pain in the head; he is dull and stupid, and requires an effort to arouse. The pulse is weak and quick; the hæmorrhage has continued from the ear; it is florid, and although less in quantity than yesterday, yet it is considerable; that from the nose and mouth has ceased. The eyes are now completely surrounded by black rings of ecchymoses; the lids are much swelled, and it is with difficulty that the eye can be seen; the pupils act; the conjunctivæ continue slightly ecchymosed; the bowels have acted freely. Cold lotion to be applied to the head. Low diet.

6. He passed a better night. There is still a difficulty in making him understand the questions put to him, appearing disinclined to arouse; the bleeding has continued from the ear; it is of a paler color; the eyelids are so much swollen that they cannot be separated; he often asks for water; the tongue is furred, but moist; the pulse weak and quick; the scalp is swelled; the wound looks healthy; bowels act freely. Calomel, two grains; opium, half a grain; every three hours.

9. The symptoms have continued, with slight alterations, up to this time; the discharge continues from the ear; it is a thin watery discharge tinged with blood; the eyelids are painful and inflamed; the ecchymosis is going off; he is much more intelligent; he states that the pain in the head is less; he speaks very loud, and complaing of a great noise in his head, like the strokes of an engine. The wound is healthy. Omit calomel and opium.

12. An abscess has formed in the left eye which was punctured; the discharge from the right ear has become purulent, slightly tinged with blood. He continues to complain of the loud noises in the head. The mouth is very sore from the mercury. The wound is nearly healed; the swelling of the eyelids is nearly gone; the ecchymosis has quite disappeared; and he expresses himself as "feeling more like himself and much better."

14. He complains this morning of great difficulty of vision with the right eye; the pupil of this eye acts irregularly; there is paralysis of the upper lid of the right eye, which was not observed before; he cannot hear distinctly with the right ear, and has lost the sense of smell; the discharge of matter continues in considerable quantity from the ear; the gums continue very sore; he expresses a desire to leave his bed and to have better food; he complains of the noise, but describes it as more like the sound of the bubbling of boiling water than anything else; the wound is quite healed; continues the low diet.

16. The symptoms continue the same as at the last report.

20. He complains of pain over the fore part of the head; the pulse, which had come down to 80 , was now at 106 ; the tongue is more furred, and dry in the centre. It appears that this man has had the half diet of the house for two days by mistake, which consists of some animal food. The discharge continues from the ear; it is of a healthy character ; the paralysis continues much the same; the hearing he thinks improved, and the sense of smell has slightly returned, and he fancies he can see objects more clearly with the right eye; on holding up a finger, half a yard from the eye, he could not tell what object was held up. Twelve leeches to the temples; half an ounce of castor oil at once. Diet as before.

21. The pain in the head and fever are quite re. lieved, and he appears as well as before the attack.

30. The discharge of matter continues from the ear; it is of a healthy character; he has lost the unpleasant sensation of sounds in the head; the right pupil acts better; the paralysis of the right lid continues the same; he can distinguish objects at two yards off with the right eye; he has the sense of smell stronger, being able now to distinguish strong odors.

July 5. He is improving each day; the matter from the ear is diminishing in quantity; the sight of the right eye is stronger, particularly when he first awakes in the morning; the right pupil continues much more dilated than the left; the paralysis of the lid is the same.

9. The discharge from the ear has quite ceased, and, with the exception of the paralysis of the eyelid, he is in every respect better. Allowed to sit up, and to have half diet.

16. He left the hospital at his own request, at which time the sight of the right eye was much im. proved. He was able to distinguish objects at the further side of the ward in which he slept; the hearing was restored, and he was in every respect very much better.

I saw this man a few weeks after he left the hospital; he was quite well, with the exception of the paralysis of the lid, which was much better.

CAss II.-William Cain, aged twenty-seven, was admitted on the 17th of February, 1842, into hospital, with dislocation of the head of the femur into the sacro-ischiatic notch. The dislocation was well marked, and was easily reduced by the use of the pullies. The patient had fallen into the hold of a ship, and when brought into the hospital was faint; advantage was taken of this state, and rendered the reduction comparatively easy: He was perfectly sensible, complaining of cold, and a desire for bed; the surface was cold; he did not complain of any other injury.

18. He has passed a good night, and expresses himself as feeling no other than slight pain in the 
hip, and soreness about the body. The bowels have acted; the pulse is 80 ; tongue slightly furred.

20. This morning Mr. Parker, the house-surgeon, found the patient with symptoms of coma; it was with difficulty he could be roused, breathing heavily, with slow pulse. In consequence of these appearances we had the head shaved, and made a careful examination; a small tumor of effused blood was found over the left temple; slight ecchymosis was observed over the upper and lower eyelids of the left side; there was also a small spot on the conjunctiva of the left eye; there is paralysis of the left side of the face. On pressing the tumor over the temple, he shows from his movements that it gives pain; on speaking loudly and shaking him, he answers in monosyllables; the pupils are dilated; they act slightly. Cold lotion was ordered to the head; turpentine enemata were ordered, and three grains of calomel, with one and a half of opium every two hours.

21. The symptoms continue without any alteration; the bowels have been freely opened; the symptoms of coma are not increased.

22. The gums are affected by the mercury; the symptoms of compression are not increasing. Omit the calomel.

It is unnecessary to give the daily symptoms in this case s suffice it to say, that there was a rapid improvement manifested each day, and at the expiration of fourteen days from the attack the symptoms en. tirely disappeared, the patient continuing well under the influence of mercury the whole time.

\section{HYDATIDS OF THE UTERUS.}

TO THE EDITORS OF THE PROVINCIAL MEDICAL JOURNAL.

Gentlemen,-I consider that every medical man ought, as far as he can, make known to his medical brethren any case of practical value that may come under his observation, and more especially that every member of the Provincial Medical and Surgical Association should publish such in your excellent Journal. This being my opinion, I send you the following case of hydatids of the uterus, which, if you consider of sufficient interest, shall be obliged by your insertion of it in the Journal :-

On the 8 th of December last I was sent for, about three, a.m., to attend Mrs. H., of this place, then in labor. On my arrival I found the presentation natural, and delivery took place in about an hour; in fact, the labor was a common-place one, and the patient went on well till the 20 th, when her husband came in a great hurry, desiring me to see his wife immediately, as he was afraid she was dying. I hastened to her house, and found her in a state of syncope. Profuse hæmorrhage had taken place, and was still continuing; two chamber utensils had been emptied prior to my arrival; the one I saw was more than half full, and the bed-clothes were saturated with blood. I immediately ordered cloths wet with vinegar and water to be applied over the abdomen, loins, thighs, \&c., while I went for some ammonia and opium, which might have taken me about ten minutes. On my return I found that the hæmorrhage had entirely ceased, and on giving her the stimulant she rallied.
I now made inquiries into the particulars of the case. It appeared that she got out of bed in the morning, and on returning found something running away from her, and directly she felt a substance come away, which, on examination I found to be a mass of hydatids. I cannot describe the size better than in the words of a woman present--"Why, Sir, it is as large as a child's head." I called again in the course of the day, and found there had been no return of the hæmorrhage, and in a few days the patient was down stairs quite recovered, except being weak from the great loss of blood.

I beg to remark two circumstances in this case which I consider rather extraordinary; first, the manner in which the hydatids came off (I cannot say expelled), for it appears there was no uterine contraction; it must have been from their own weight; secondly, the sudden stoppage of the hæmorrhage, for, after the cold application, there was not sufficient to stain a napkin.

I am, Gentlemen, Your obedient servant, F. A. Clewe.

Bradninch, Jan. 14, 1843.

\section{REMARKS ON CHOLERA.}

TO THE EDITORS OF THE PROVINCIAL MEDICAL JOURNAL.

Gentlemen,-The subject which now claims attention is the state of the circulation in cholera, and it may be very advantageously divided into two heads - viz., the action of the organs by which the circulation is carried on, and the condition of the circulating fluid.

1st. Of the action of the heart and arteries. From what has been already said, it will be inferred that the heart and arteries are impaired in action, whether the force or frequency of their contractions be regarded, and in this respect correspond most remarkably with the respiration. From what was stated in a former letter, it might be supposed that this state of the circulation was to be imputed solely to the imperfectly oxygenated blood supplied to the heart, owing to the defective action of the lungs; but in cholera other circumstances exist, the tendency of which is to prohibit such an exclusive explanation. No fact in physiology or pathology is better known, or more easy of demonstration, than the mutual dependence on each other of the respiratory and circulatory systems-in other words, the normal action of the lungs is essential to healthy circulation, and so is a healthy condition of the latter to the function of respiration. Hence it is, that where the heart is diseased the respiratory system is sooner or later a participator; and where the function of respiration is materially disordered, such derangement almost immediately implicates the circulation. In such cases, however, one system is unequivocally affected in consequence of the deranged state of the other; and whilst the action of the one is increased that of the other may be absolutely diminished, and vice versi -in fact they may be regarded simply as cause and effect. What, then, it may be asked, is the peculiarity connected with these systems in cholera? Is it that, so far as my observation extends, the most perfect correspondence between the 